\title{
Patient with alcoholic dilated cardiomyopathy and anomalous origin of supernumerary left anterior descending artery
}

\author{
DSilvija Miletić \\ Gršković*, \\ Vedran Buršić, \\ (iD)Adrian Trobonjača, \\ (D) Viktor Peršić
}

Clinic for rehabilitation, treatment and prevention of diseases of the heart and blood vessels, Thalassotherapia Opatija, Croatia

RECEIVED:

February 28, 2019

ACCEPTED:

March 24, 2019

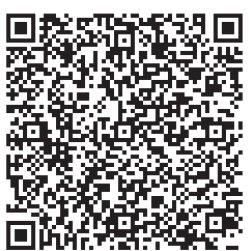

$\square$ Cardiologia Croatica 2019:14(3-4):100.
KEYWORDS: anomalies, coronary vessel, cardiomyopathy.

CITATION: Cardiol Croat. 2019;14(3-4):100. | https://doi.org/10.15836/ccar2019.100

*ADDRESS FOR CORRESPONDENCE: Silvija Miletić Gršković, Thalassotherapia Opatija, M. Tita 188/1, HR-51410 Opatija, Croatia. / E-mail: silvija.miletic@gmail.com

ORCID: Silvija Miletić Gršković, https://orcid.org/0000-0001-7763-726X • Adrian Trobonjača, https://orcid.org/0000-0001-9581-8718 Viktor Peršić, https://orcid.org/0000-0003-4473-5431

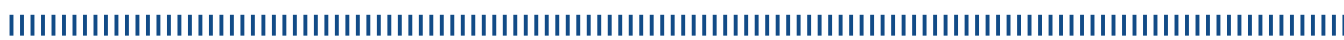

Case report: 46-years-old patient with positive family anamnesis of cardiovascular diseases was presented in Special Hospital Magdalena in January 2017 with fatigue and chest pain. Cardiology work up revealed dilated cardiomyopathy (EF 20\%), moderate mitral regurgitation and thrombus in left ventricle. On a second day of hospitalization patient was diagnosed with left popliteal artery embolism. After the treatment with low molecular heparin, thrombus was dissolved, and popliteal artery was recanalized. He continued anticoagulation therapy with warfarin. During hospitalization another complication occurred. Left sided pneumonia was successfully treated with azithromycin and ceftriaxone. Beside his cardiological problems, hepatic lesion was also verified. The etiology of hepatic lesion was probably alcohol abuse as it was for dilated cardiomyopathy ${ }^{1}$. In February 2018. invasive coronarography showed anomalous origin of left anterior descending artery from right coronary sinus with intact coronary arteries. Echocardiography was performed and there was an improvement of left ventricular ejection fraction (50\%) and a sign of mild mitral regurgitation. In our hospital, MSCT coronarography verified anomalous origin of one left anterior descending artery from right coronary sinus, at the level of the exit of right coronary artery, with „bridging" along the whole proximal segment. Left main coronary artery exits from left coronary sinus from where arises (except circumflex artery) another left anterior descending artery running in normal anatomic position along left ventricle with all developed branches, septals and diagonals ${ }^{2}$. Magnetic resonance imaging showed dilated cardiomyopathy with ejection fraction $40 \%$; nonspecific, stationary deficit of perfusion in intraventricular septum and inferior wall with typical pathological imbibition of myocardium, "midventricular type", in post-contrast sequences. This sign is typical for toxic, dilated cardiomyopathy. This heart with coronary arteries is 3D printed.

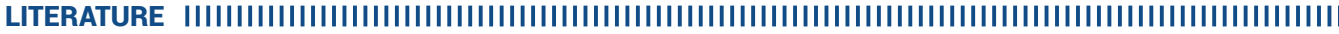
1. Bryson CL, Mukamal KJ, Mittleman MA, Fried LP, Hirsch CH, Kitzman DW, et al. The association of alcohol consumption and incident heart failure: the Cardiovascular Health Study. J Am Coll Cardiol. 2006 Jul 18;48(2):305-11. https://doi.org/10.1016/j.jacc.2006.02.066

2. Roberts WC. Major anomalies of coronary arterial origin seen in adulthood. Am Heart J. 1986 May;111(5):941-63. https://doi.org/10.1016/0002-8703(86)90646-0 